\title{
Mortality trends in the City of Cape Town between 2001 and 2013: Reducing inequities in health
}

\author{
P Groenewald, ${ }^{1} \mathrm{MB}$ ChB, MPhil (Public Health); I Neethling, ${ }^{1} \mathrm{MSc} ;$ J Evans, ${ }^{2} \mathrm{PhD} ;$ V Azevedo, ${ }^{3} \mathrm{MB}$ ChB; $\mathbf{T}$ Naledi, ${ }^{2} \mathrm{MB} \mathrm{ChB}, \mathrm{FCPHM}(\mathrm{SA}) ;$ \\ R Matzopoulos, ${ }^{1}$ BBusSci, MPhil (Epidemiology), PhD (Public Health); N Nannan, ${ }^{1}$ MSc (Molecular Biology), MSc (Medical Demography); \\ J Daniels, ${ }^{3}$ Dip Acupuncture, MPH; D Bradshaw, ${ }^{1}$ MSc, DPhil (Oxon)
}

\author{
${ }^{1}$ Burden of Disease Research Unit, South African Medical Research Council, Cape Town, South Africa \\ ${ }^{2}$ Western Cape Government: Health, Cape Town, South Africa \\ ${ }^{3}$ City Health, City of Cape Town, South Africa
}

Corresponding author: P Groenewald (pamela.groenewald@mrc.ac.za)

\begin{abstract}
Background. The City of Cape Town (CoCT), South Africa, has collected cause-of-death data from death certificates for many years to monitor population health. In 2000, the CoCT and collaborators set up a local mortality surveillance system to provide timeous mortality data at subdistrict level. Initial analyses revealed large disparities in health across subdistricts and directed the implementation of public health interventions aimed at reducing these disparatities.

Objectives. To describe the changes in mortality between 2001 and 2013 in health subdistricts in the CoCT.

Methods. Pooled mortality data for the periods 2001 - 2004 and 2010 - 2013, from a local mortality surveillance system in the CoCT, were analysed by age, gender, cause of death and health subdistrict. Age-specific mortality rates for each period were calculated and agestandardised using the world standard population, and then compared across subdistricts.

Results. All-cause mortality in the CoCT declined by 8\% from 938 to 863 per 100000 between 2001 - 2004 and 2010 - 2013. Mortality in males declined more than in females owing to a large reduction in male injury mortality, particularly firearm-related homicide. HIV/ AIDS and tuberculosis (TB) mortality dropped by $\sim 10 \%$ in both males and females, but there was a marked shift to older ages. Mortality in children aged $<5$ years dropped markedly, mostly owing to reductions in HIV/AIDS and TB mortality. Health inequities between subdistricts were reduced, with the highest-burden subdistricts achieving the largest reductions in mortality.

Conclusions. Local mortality surveillance provides important data for planning, implementing and evaluating targeted health interventions at small-area level. Trends in mortality over the past decade indicate some gains in health and equity, but highlight the need for multisectoral interventions to focus on HIV and TB and homicide and the emerging epidemic of non-communicable diseases.
\end{abstract}

S Afr Med J 2017;107(12):1091-1098. DOI:10.7196/SAMJ.2017.v107i12.12458

The monitoring of inequity is an emerging priority for health post2015, with the sustainable development goals specifically calling for reduction of inequity within and among countries. ${ }^{[1]}$ These go further to highlight the importance of producing reliable data at subnational level, to identify where inequities exist and to ensure that policies reach the most vulnerable populations. Mortality indicators are used as key criteria to assess population health globally. Specifically, child mortality has been used as a universal indicator of inequality because it is sensitive to socioeconomic change and therefore extensively used by international agencies to compare health and socioeconomic progress between regions and individual countries. ${ }^{[2]}$

Since 1994, the South African (SA) government has highlighted the importance of addressing inequities that reflect the legacy of apartheid. Inequalities in provincial mortality in 2000 were highlighted by stark differences in under-5 (U5) mortality, where two of the poorest provinces, KwaZulu-Natal and the Eastern Cape, had rates 2.5 and 2.3 times higher, respectively, than the richest province, the Western Cape ${ }^{[3]}$ Similar differentials in other key health indictors were also evident; for example, the overall age-standardised mortality rates (ASDMRs) in KwaZulu-Natal and Mpumalanga provinces were 1.5 times higher than in the Western Cape. The average provincial profile, however, masks the variability within a province.

The City of Cape Town (CoCT) is one of the six major metropolitan areas in SA, with a population of $\sim 3.7$ million people. Recognising that mortality data are important for monitoring population health and evaluating the impact of health interventions, the CoCT health directorate has collected cause-of-death data from death certificates for many years. From the early 2000s the CoCT, the University of Cape Town (UCT) and the Medical Research Council collaborated to set up a local mortality surveillance system (LMSS) that would address some of the problems with the national vital registration system at the time. ${ }^{[4]}$ These included the long lag time for producing national cause-of-death reports (up to 5 years) and the lack of reporting at subdistrict level, the smallest unit of health management. In addition, the national injury mortality profile is inaccurate because forensic pathologists are reluctant to report the manner of death on the death certificate for fear of contravening section 20.4 of the Inquest Act. ${ }^{[5]}$ The LMSS obtained additional information on manner of death from forensic mortuaries to provide accurate injury mortality statistics. An analysis of these data from 2001 to 2006 identified the leading causes of premature mortality and highlighted the disparities in health between subdistricts in the CoCT, providing valuable information for local health managers. ${ }^{[6]}$ Considerable variation in mortality rates was observed between health subdistricts.

The Department of Health of the Provincial Government of the Western Cape (DoH) joined this collaboration in 2007 and expanded the surveillance to the rest of the Western Cape as part of a provincial project aiming to reduce the burden of disease and promote equity in health. ${ }^{[7,8]}$ To support this expansion, the CoCT undertook significant IT development of the LMSS, moving from a personal 
computer-based system to a web-based system. In addition, cause-ofdeath coding was upgraded from manual coding using a shortlist to automated ICD-10 (International Statistical Classification of Diseases and Related Health Problems, 10th revision) coding using IRIS version V4.1.3 (IRIS Institute, DIMDI, Germany). ${ }^{[9]}$ Regular reports on the mortality profile of the city and subdistricts, and later for all subdistricts across the province, were produced and widely used by the health and other sectors in the province, to plan interventions aimed at reducing mortality and improving health.

\section{Objectives}

To update the 2001 - 2006 analysis and describe the changes in mortality, including child mortality, and health inequities between 2001 and 2013 in the CoCT and subdistricts.

\section{Methods \\ Study setting}

The CoCT still has wide disparities between communities, with the affluent living in developed-world conditions while the poor live in informal housing in crowded and unsanitary conditions. The eight health subdistricts encompass a mix of upper-, middleand low-income areas, including very poor periurban informal settlements. Census 2011 highlighted the socioeconomic inequities between subdistricts, which mirror the mortality differentials, with the percentage of households earning less than the poverty line of ZAR1 320 (USD216) per month ranging from $30 \%$ in the more affluent subdistricts to $74 \%$ in the poorest (Appendix 1). All supplementary information (Appendices 1-6) is available online (http://www.mrc.ac.za/bod/coct.htm).

\section{Data sources}

Health officials collected copies of death certificates registered at local home offices in the CoCT and captured demographic and cause-ofdeath data into an access-controlled web-based database. In $~ 70 \%$ of the deaths after 2008 , the underlying cause was automatically coded to ICD-10 using IRIS software. This required capture of the multiple causes of death using text. The rest were coded manually by DoH staff trained in ICD-10 coding. Before 2007, reported causes of death were coded manually to a shortlist by trained clerks and only the underlying cause was captured. The underlying cause of death is defined in the ICD-10 classification ${ }^{[10]}$ as '(a) disease or injury which initiated the train of morbid events leading directly to death, or (b) the circumstance of the accident or violence which produced the fatal injury. Forensic mortuary records were obtained annually from forensic pathology services and linked with the death certificate data using unique identifiers that appear in both sets of data, as well as date of birth, date of death, gender and race. The unique identifiers included the death certificate serial number and the mortuary reference number. The anonymised linked data were made available for analysis.

\section{Data processing}

To provide useful information for policy-making, deaths with illdefined causes were redistributed proportionally by age and gender across specified causes of death, the assumption being that the cause profile of the ill-defined deaths would match the cause profile of the specified deaths. In addition, certain algorithms were developed to recode causes likely to be misclassified. Where euphemisms for HIV/AIDS such as immunodeficiency, immunocompromised or retroviral disease were reported, these deaths were recoded to HIV/ AIDS throughout both periods. In the second period, hypertension reported alone was treated as an ill-defined cause and redistributed across other specified causes, thus accounting for much of the decline in mortality from hypertension. In addition, where stroke or ischaemic heart disease (IHD) were reported with diabetes mellitus, these deaths were coded to stroke or IHD rather than diabetes, as was done in the first period. It was not possible to recode the causes from the first period, as only the underlying cause code was captured at that stage. To reduce the large proportion (25\%) of deaths with illdefined causes among U5 children, ${ }^{[11]}$ record reviews were conducted to identify the cause of death for all ill-defined child deaths reported at forensic mortuaries during the second period. This revealed that a large proportion of sudden unexpected deaths in young children were due to lower respiratory tract infection (LRTI). ${ }^{[11]}$

\section{Data analysis}

Pooled data from 2001 - 2004 and 2010 - 2013 were analysed by age, underlying cause of death, gender and subdistrict to reduce the chance of misinterpreting year-on-year variations in single causes, and take account of poor completeness of the data between 2005 and 2009 due to logistical issues affecting the surveillance system. Completeness was assessed by comparing the total deaths reported to the LMSS for the CoCT with totals from the population register of the Department of Home Affairs and vital registration data from Statistics South Africa for the period 2001 - 2013 (Appendix 2). ${ }^{[12]}$ Cause-of-death shortlist codes from the period 2001 - 2004 were mapped to the National Burden of Disease list, ${ }^{[13]}$ resulting in 67 single causes of death for analysis (Appendix 3). These comprised four broad cause groups: (i) HIV/AIDS and tuberculosis (TB); (ii) pre-transitional causes (other communicable diseases, maternal causes, perinatal conditions and nutritional deficiencies); (iii) noncommunicable diseases (NCDs); and (iv) injuries. Deaths in U5 children were further aggregated into 11 causes including HIV/ AIDS, TB, LRTI, meningitis, diarrhoea, septicaemia, malnutrition, congenital abnormalities, injuries and other. This cause list was adapted from the list used by the Child Health Epidemiology Reference Group. ${ }^{[14]}$ Population estimates for health subdistricts were estimated from Western Cape provincial estimates produced by the Centre for Actuarial Research, UCT, ${ }^{[15]}$ using the ratio method. Age-specific mortality rates (ASMRs) per 100000 population were calculated and then age-standardised using the world standard population, ${ }^{[16]}$ and compared across subdistricts. Confidence intervals for ASDMRs were calculated using a Poisson approximation method described by Boyle and Parkin. ${ }^{[17]}$

\section{Results}

The all-cause mortality rate for persons of all ages declined by $8 \%$ from 938 to 863 per 100000 between 2001 - 2004 and 2010 - 2013 (Table 1). Mortality rates for males remained higher than those for females, with mortality differentials of 1.6 in 2001 - 2004 declining to 1.5 in 2010 - 2013, indicating a larger reduction in mortality for males $(9.3 \%)$ than for females $(6.6 \%)$ over this period. There were large mortality differentials between subdistricts, with Khayelitsha having 1.9 times the mortality of Northern in the early period. However, reductions in mortality achieved in the three highestburden subdistricts, Khayelitsha, Klipfontein and Mitchell's Plain, were much higher than in the other subdistricts, thus reducing the mortality differentials in the later period (Table 1).

All-cause mortality rates declined across all age groups; however, the largest declines occurred in children aged $<10$ years, followed by young adults between 15 and 34 years of age (Table 2). Over the entire period, all-cause mortality rates dropped in U5 children, by $22.5 \%$ from 577.6 to 447.6 per 100000 . The largest percentage declines 
Table 1. All-cause ASDMRs ${ }^{\dagger}$ by gender and district, CoCT, 2001 - 2004 and 2010 - 2013

\begin{tabular}{|c|c|c|c|c|c|}
\hline & \multicolumn{2}{|c|}{$\operatorname{ASDMR}(95 \% \mathrm{CI})$} & \multirow[b]{2}{*}{ Change in ASDMR (\%) } & \multicolumn{2}{|c|}{ ASDMR ratio } \\
\hline & $2001-2004$ & $2010-2013$ & & $2001-2004$ & $2010-2013$ \\
\hline \multicolumn{6}{|l|}{ Gender } \\
\hline Male & $1167\left(\begin{array}{llll}1 & 157-1 & 178)\end{array}\right.$ & $1058(1049-1067)^{*}$ & -9.3 & 1.6 & 1.5 \\
\hline Female & $750(743-757)$ & $700(694-707)^{*}$ & -6.6 & 1 & 1 \\
\hline Persons & $938(932-944)$ & $863(858-868)^{*}$ & -8.0 & & \\
\hline \multicolumn{6}{|l|}{ Subdistrict } \\
\hline Khayelitsha & $1352(1314-1390)$ & $1093(1064-1123)^{*}$ & -19.1 & 1.9 & 1.7 \\
\hline Klipfontein & 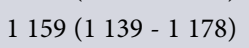 & $993(976-1010)^{*}$ & -14.3 & 1.7 & 1.5 \\
\hline Mitchell's Plain & $1053(1027-1079)$ & $949(928-969)^{*}$ & -9.9 & 1.5 & 1.5 \\
\hline Tygerberg & $1002(986-1018)$ & $934(920-948)^{*}$ & -6.8 & 1.4 & 1.4 \\
\hline Eastern & $867(850-884)$ & $845(831-860)$ & -2.5 & 1.2 & 1.3 \\
\hline Western & $843(827-858)$ & $828(814-842)$ & -1.7 & 1.2 & 1.3 \\
\hline Southern & $738(726-751)$ & $734(723-745)$ & -0.6 & 1.1 & 1.1 \\
\hline Northern & $699(682-715)$ & $652(639-655)^{*}$ & -6.7 & 1.0 & 1.0 \\
\hline CoCT & $938(932-944)$ & $863(858-868)^{*}$ & -8.0 & 1.3 & 1.3 \\
\hline
\end{tabular}

Table 2. All-cause ASMRs, CoCT, 2001 - 2004 and $2010-2013$

\begin{tabular}{llll}
\hline \multirow{2}{*}{$\begin{array}{l}\text { Age group } \\
\text { (years) }\end{array}$} & \multicolumn{2}{c}{ Deaths per $\mathbf{1 0 0} \mathbf{0 0 0}$ population } & Change in \\
\cline { 2 - 4 } & $\mathbf{2 0 0 1 - 2 0 0 4}$ & $\mathbf{2 0 1 0} \mathbf{- 2 0 1 3}$ & ASMR (\%) \\
\hline $0-4$ & 577.6 & 447.6 & -22.5 \\
$5-9$ & 50.3 & 34.8 & -30.9 \\
$10-14$ & 43.1 & 42.4 & -1.6 \\
$15-19$ & 185.2 & 147.1 & -20.6 \\
$20-24$ & 343.4 & 274.0 & -20.2 \\
$25-29$ & 456.1 & 352.2 & -22.8 \\
$30-34$ & 507.8 & 420.0 & -17.3 \\
$35-39$ & 552.8 & 514.3 & -7.0 \\
$40-44$ & 638.5 & 593.6 & -7.0 \\
$45-49$ & 805.2 & 762.0 & -5.4 \\
$50-54$ & 1074.6 & 1041.3 & -3.1 \\
$55-59$ & 1456.7 & 1379.0 & -5.3 \\
$60-64$ & 2101.2 & 1928.0 & -8.2 \\
$65-69$ & 2853.8 & 2700.4 & -5.4 \\
$\geq 70$ & 6382.9 & 6245.0 & -2.2 \\
ASMR = age-specific mortality rate; CoCT & City of Cape Town. & \\
& & &
\end{tabular}

$(41.6 \%, 32.9 \%)$ in U5 mortality rates occurred in Khayelitsha and Klipfontein, respectively (Table 3).

This decline in U5 mortality was mainly due to the almost eight-fold decline in HIV/AIDS mortality in the CoCT, with U5 HIV mortality dropping more than ten-fold in Khayelitsha, Klipfontein, Mitchell's Plain and Western (Fig. 1). Smaller declines were noted in diarrhoea, perinatal causes and injuries. Khayelitsha had a particularly dramatic decline in child HIV/AIDS mortality, dropping from 230.5 to 21.1 deaths per 100000 population in U5 children (Fig. 1), followed by a drop from 191.7 to 15.2 deaths per 100000 in U5 children in Klipfontein.

The ASMRs for the four broad causes of death in $2001-2004$ and $2010-2013$ are shown in Fig. 2. Apart from the marked decrease in HIV/AIDS and TB death rates in U5 children, the mortality rates highlight the shift in the HIV/AIDS mortality peak in adults to older ages. This has occurred despite an increase in the prevalence of HIV infection in antenatal women from $8.6 \%$ in 2001 to $18.5 \%$ in 2010 in the Western Cape. ${ }^{[18]}$ In addition, a marked decrease was noted in male injury death rates from 15 years up, with the largest decline in the 20 - 29-year age group. While the injury rates in the oldest age group increased, they are based on smaller numbers of cases and may be related to better-quality information in the latter period.

Table 3. U5 mortality rates by subdistrict, CoCT, 2001 - 2004 and 2010 - 2013

\begin{tabular}{|c|c|c|c|c|c|}
\hline \multirow[b]{2}{*}{ Subdistrict } & \multicolumn{2}{|c|}{ U5 deaths per 100000 population } & \multirow{2}{*}{$\begin{array}{l}\text { Change in U5 } \\
\text { mortality rate (\%) }\end{array}$} & \multicolumn{2}{|c|}{ U5 mortality rate ratio } \\
\hline & $2001-2004$ & $2010-2013$ & & $2001-2004$ & $2010-2013$ \\
\hline Khayelitsha & 976.6 & 570.2 & -41.6 & 2.4 & 1.7 \\
\hline Klipfontein & 671.8 & 450.8 & -32.9 & 1.7 & 1.3 \\
\hline Northern & 571.8 & 465.4 & -18.6 & 1.4 & 1.4 \\
\hline Eastern & 567.4 & 479.7 & -15.4 & 1.4 & 1.4 \\
\hline Mitchell's Plain & 511.4 & 445.0 & -13.0 & 1.3 & 1.3 \\
\hline Western & 494.0 & 429.1 & -13.1 & 1.2 & 1.3 \\
\hline Tygerberg & 443.3 & 400.5 & -9.7 & 1.1 & 1.2 \\
\hline Southern & 402.5 & 341.0 & -15.3 & 1.0 & 1.0 \\
\hline СoCT & 577.6 & 447.6 & -22.5 & 1.4 & 1.3 \\
\hline
\end{tabular}




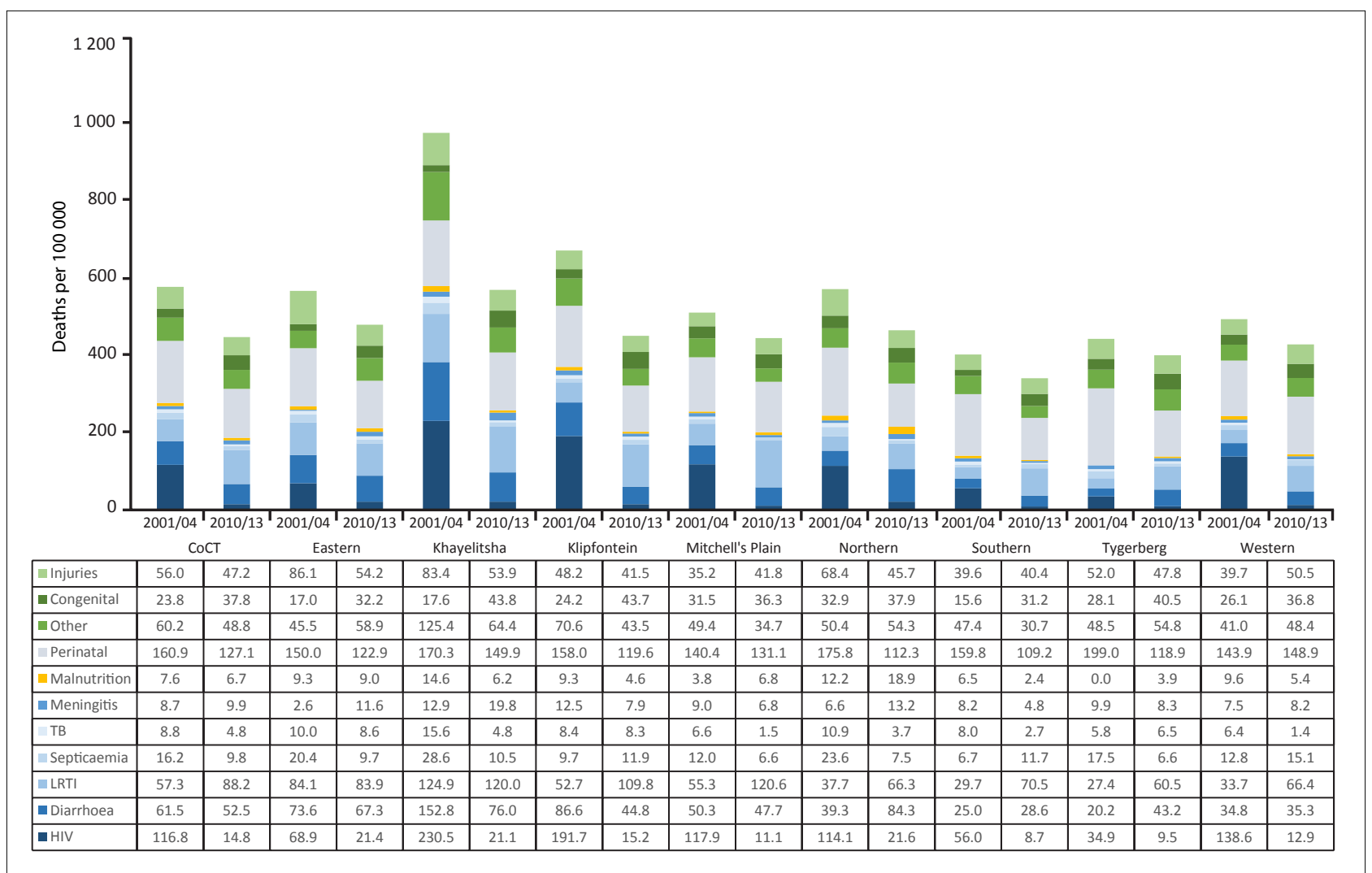

Fig. 1. Cause-specific mortality rates in children aged $<5$ years by subdistrict, CoCT, $2001-2004$ and $2010-2013$. (CoCT = City of Cape Town; LRTI = lower respiratory tract infection.)

No significant changes were noted in age-specific death rates due to NCDs and other communicable, maternal, perinatal and nutritional conditions.

\section{HIV/AIDS and tuberculosis}

The peak HIV/AIDS and TB mortality rate for adult women decreased slightly from 219.5 to 204.6 per 100000 population between 2001/04 and 2010/13, and shifted to older ages. In contrast, among adult males the peak mortality rate increased slightly from 263.7 to 268.6 per 100000 , also with a shift to older ages.

The subdistrict trends in ASDMRs for HIV/AIDS and TB are shown in Fig. 3. HIV/AIDS ASDMRs declined significantly between $2001-2004$ and 2010 - 2013 in both males and females in Klipfontein and Western and in females in Khayelitsha. Agestandardised TB mortality rates in males in Khayelitsha declined dramatically, with a smaller reduction among Khayelitsha females. A small but significant decline in male age-standardised TB mortality rates occurred in Klipfontein. Across the city the decline in HIV/AIDS and TB all-cause ASDMR accounted for $15.9 \%$ of the all-cause ASDMR reduction (data not shown). In Khayelitsha and Klipfontein, however, the decline in HIV/AIDS and TB ASDMRs accounted for $34 \%$ and $22 \%$ of the ASDMR reduction, respectively (data not shown).

Age-specific HIV/AIDS and TB mortality rates in $2001-2004$ and $2010-2013$ for the three highest-burden subdistricts, namely Khayelitsha, Klipfontein and Mitchell's Plain, are shown in Appendix 4. HIV/AIDS mortality reduced markedly in U5 children in all three subdistricts. There was a marked reduction in the female HIV peak, with a shift to older ages, and a marked reduction in female TB mortality across all ages in Khayelitsha, despite an increase in
HIV prevalence from $22 \%$ to $37 \%$ in antenatal women between 2001 and $2010^{[19,20]}$ and an increase in reported overall TB incidence from 1255 to 1444 per 100000 in Khayelitsha between 2003 and 2010 (Dr Tracey Naledi, personal communication, 30 May 2017). However, there was little change in female TB mortality in the other subdistricts. Among males, the HIV peak increased with a shift to older ages in both Khayelitsha and Mitchell's Plain, and there was a marked reduction in TB mortality across all ages in adult males in Khayelitsha, less so in Klipfontein, and little change in Mitchell's Plain.

\section{Injuries}

A closer investigation of male injury death rates by single cause revealed a large decline in homicide ASDMRs (113.3 to 84.5 per 100 000), a slight decrease in road traffic injury ASDMRs (40.1 to 35.3 per 100000 ), and a slight increase in suicide ASDMRs (14.0 to 18.7 per 10000 ) (Appendix 5).

Firearm-related homicide ASDMRs in the CoCT decreased markedly from 52.5 to 31.5 per 100000 , compared with non-firearm homicide (60.8 to 53.0 per 100000 ) (Fig. 4). While firearm-related homicide declined across all ages, ASMRs in non-firearm homicide increased slightly from 91.0 to 98.8 per 100000 between 2001 and 2013, in males 15 - 19 years of age (data not shown). Khayelitsha, Klipfontein and Mitchell's Plain subdistricts had the highest agestandardised male homicide mortality rates in 2001 - 2004, with significant declines in firearm-related homicide by 2010 - 2013, along with the Southern and Western subdistricts (Fig. 4). In contrast, male firearm-related homicide rates in Tygerberg showed a worrying upward trend, although this did not reach significance. There were small but significant declines in male non-firearm related age-standardised homicide rates in Eastern, Northern and Tygerberg. 


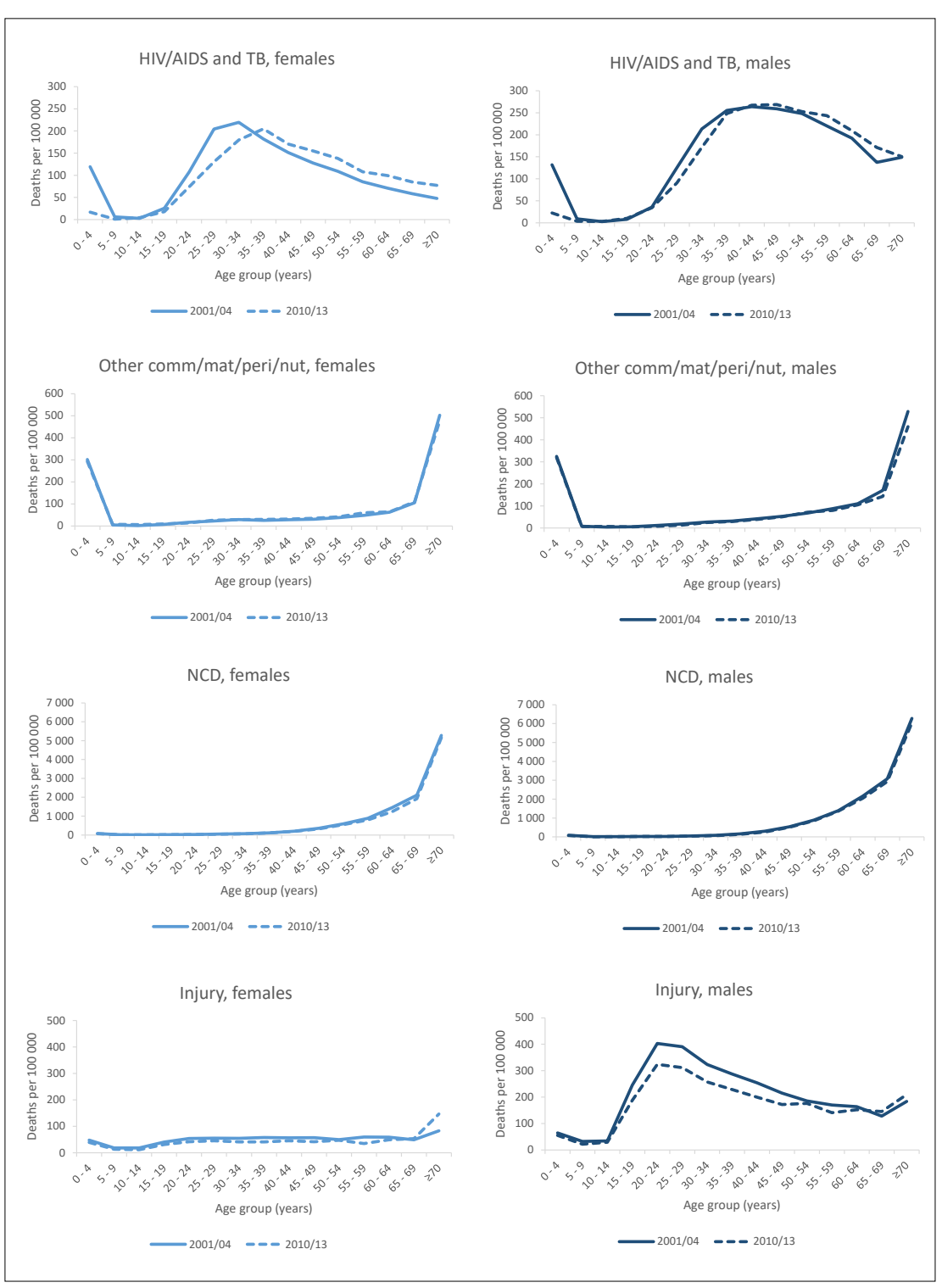

Fig. 2. Age-specific mortality rates for broad causes of death, CoCT, 2001 - 2004 and 2010 - 2013. (CoCT = City of Cape Town; $T B=$ tuberculosis; comm/mat/peri/nut = communicable, maternal, perinatal and nutritional conditions; NCD = non-communicable disease.)

A comparison of the ASMRs for male firearm-related homicide shows a marked reduction in the peak age group of 20 24 years in Khayelitsha, Klipfontein and Mitchell's Plain (Fig. 5). In contrast, there was very little change in non-firearm homicide rates in Khayelitsha and Mitchell's Plain. However, in Klipfontein, the peak in male non-firearm homicide increased in the 2010 2013 and shifted to a younger age group.

\section{Other causes of death}

The coding changes affecting cardiovascular and metabolic diseases described above make interpretation of the changes between 2001 and 2013 by single cause difficult, particularly for hypertension. However, mortality due to cardiovascular diseases such as stroke and IHD, and due to diabetes mellitus, is becoming more prominent as mortality from injuries and HIV/AIDS and TB decline, with all three appearing among the leading 10 causes of death (Appendix 6). Lung cancer and chronic obstructive pulmonary disease also rank among the leading causes of death. Increases in ASDMRs for breast, cervical and colorectal cancer were noted in women, while increases in ASDMRs for lung, colorectal and prostate cancer were noted in males (Appendix 5).

\section{Discussion}

There have been encouraging declines in mortality in the CoCT between $2001-2004$ and 2010 - 2013, with the largest declines occurring in subdistricts with the lowest socioeconomic status and the highest mortality burden, thus reducing health inequities in the city. The large reduction in child mortality has been particularly impressive in the poorer subdistricts, mainly due to plummeting HIV/AIDS mortality in children resulting from the prevention of mother-to-child transmission (PMTCT) and antiretroviral therapy (ART) rollout. Adult mortality has decreased mainly due to a decline in firearm-related homicide among young adult males, as well as a decline and delay in deaths from HIV/AIDS in young adult males and females. The decline in HIV/AIDS mortality occurred despite the doubling of HIV prevalence in antenatal women in the Western Cape over this period. Nonetheless, the mortality rates still reveal large disparities in health across the subdistricts of the CoCT, with both the ASDMR and the U5 mortality rate for Khayelitsha being 1.7 times that of Southern. However, these ratios have reduced from 1.9 for the ASDMR and 2.4 for U5 mortality in the earlier period.

The CoCT has made a concerted effort to reduce health inequities over the past 20 years. The LMSS early results identified high burden subdistricts and the leading causes of mortality, enabling the city to implement interventions to address the leading causes of premature mortality in those areas. These included health system as well as intersectoral interventions.

\section{Health system interventions}

PMTCT was implemented in Khayelitsha early in the HIV epidemic (2003). Experienced and dynamic management teams were appointed in high-burden subdistricts in 2005. Special funding streams were identified to increase resources for the TB programme. HIV and TB co-ordinators were capacitated to support both HIV/AIDS and TB programmes, including data management and analysis, to identify gaps for corrective action. Initiatives to expand PMTCT, increase HIV counselling and testing coverage, and improve the diagnosis and treatment outcomes of $\mathrm{TB}$ were undertaken across the CoCT.

In Khayelitsha, strong partnerships with non-governmental organisations allowed full integration of HIV/AIDS and TB programmes early in the epidemic. Access to the Global Fund to Fight AIDS, Tuberculosis and Malaria created the 80 new posts, for nurses, pharmacists, clerks and doctors, necessary to expand ART enrolment to all primary healthcare facilities. These posts are gradually being taken over by state health 


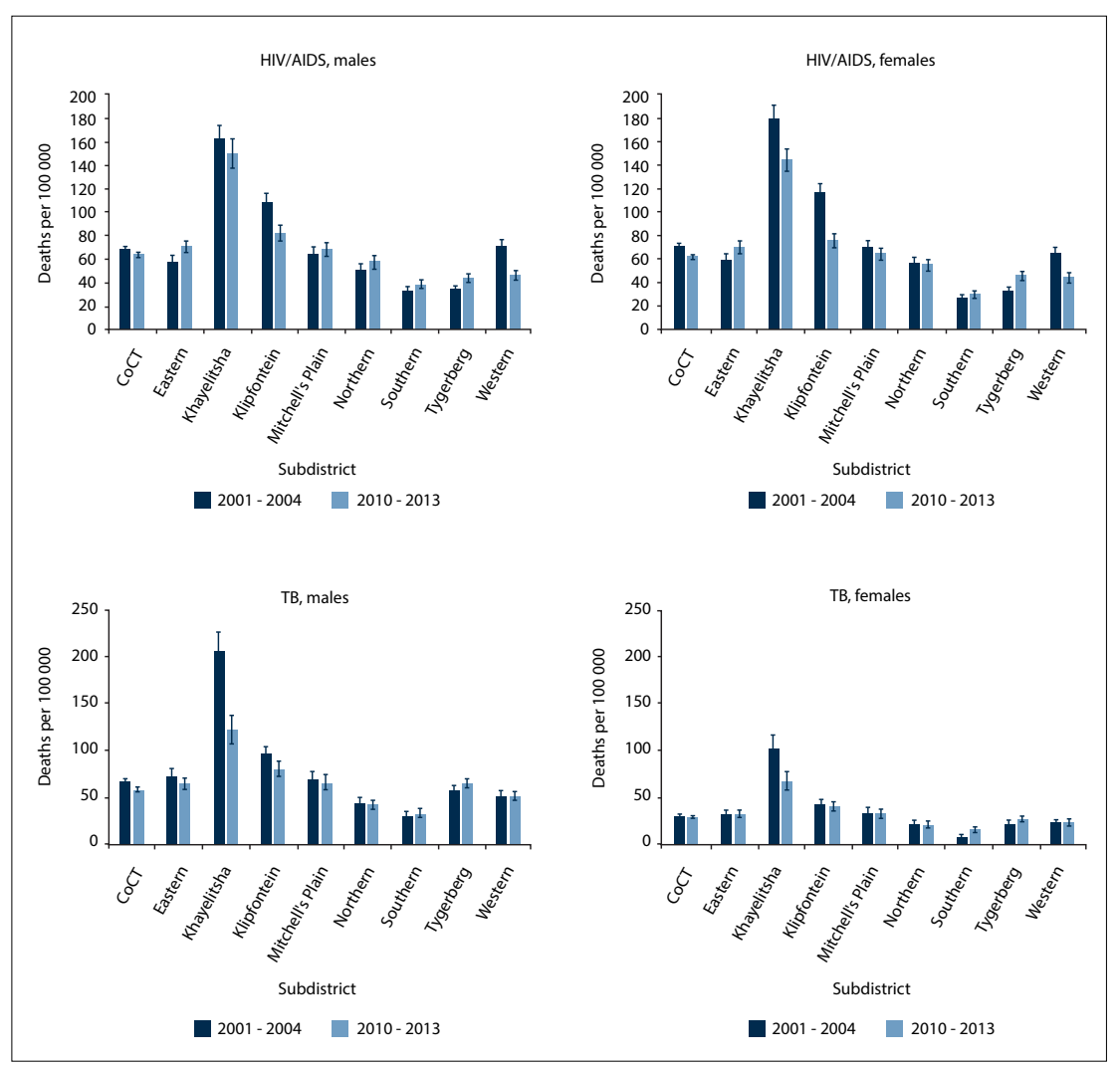

Fig. 3. Changes in HIV/AIDS and TB age-standardised mortality rates by subdistrict and gender, CoCT, between 2001 - 2004 and 2010 - 2013. (CoCT = City of Cape Town; TB = tuberculosis.)
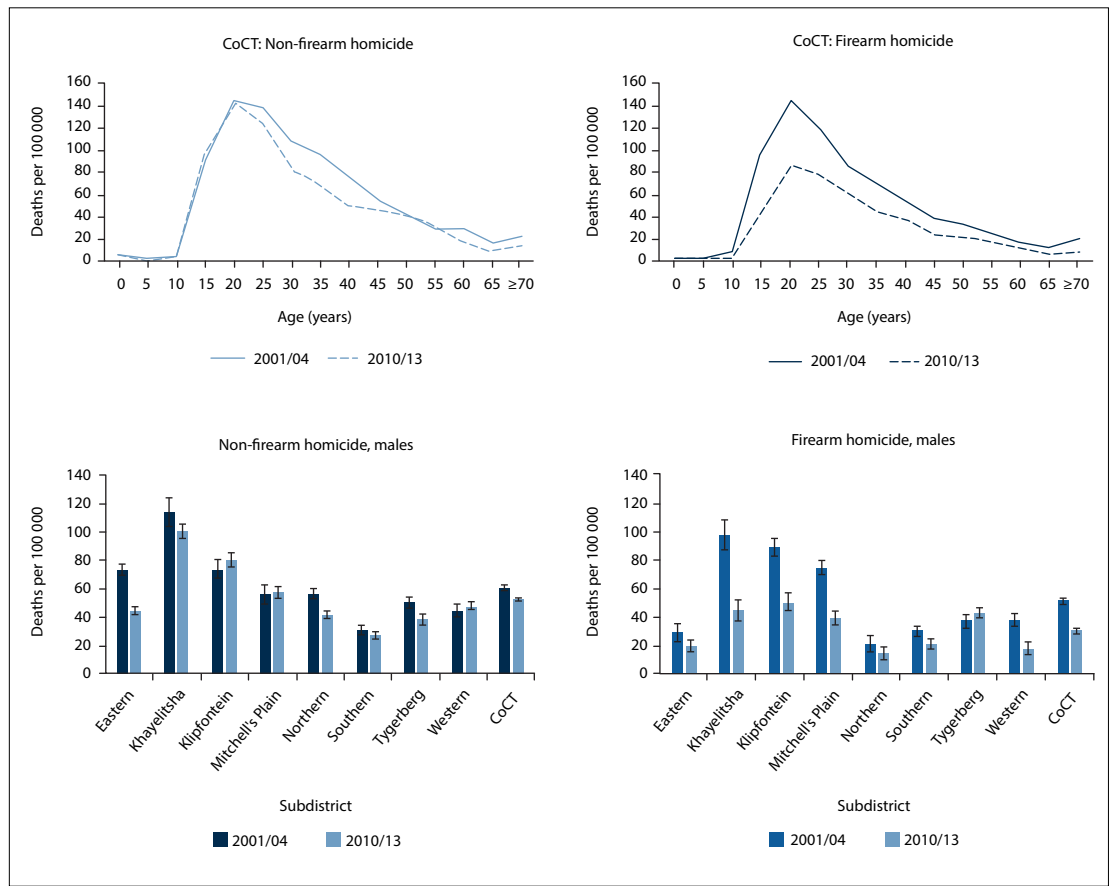

Fig. 4. Changes in non-firearm and firearm homicide mortality rates in the CoCT and subdistricts between 2001 - 2004 and 2010 - 2013. (CoCT = City of Cape Town.)

services. Innovative strategies for nurse initiation and management of ART and a rapid ART enrolment model were developed and implemented. and the Department of Community Safety were informed of the unacceptably high homicide rates in the CoCT. The provincial police commissioner implemented the People Orientated Sustainable Strategy in 2003. ${ }^{[21]}$ This identified high-priority police stations, including Khayelitsha, Nyanga, Mitchell's Plain, Gugulethu and Kuils River, and implemented measures aimed at decreasing violent crime in the areas served by these stations. These included moving directors from the provincial office to local stations, intensifying deployment, especially during high-crime periods, implementing sector policing, monitoring crime incidents, allocating additional resources, increasing the number of police stations at Khayelitsha from one to three (2005), forging partnerships with communities and opening operational centres in Khayelitsha and Nyanga. In addition, measures were taken to restrict access to alcohol in these areas by identifying and closing down illegal shebeens and enforcing shebeen trading hours.

Firearm controls were implemented in SA through the Firearms Control Act of 2000. ${ }^{[22]}$ From 2003, a more restrictive licensing regimen saw a reduction of $70 \%$ in gun licences issued. ${ }^{[23]} \mathrm{A}$ reduction in firearm homicide relative to non-firearm homicide corresponding with stricter gun control has been observed nationally, ${ }^{[24]}$ in urban $\operatorname{areas}^{[25]}$ and in the case of female homicide, ${ }^{[26]}$ suggesting that the reduction of the numbers of guns in circulation probably played a major role in the decline in firearm homicide in the CoCT.

Despite reductions in mortality from HIV/AIDS and TB and other povertyrelated conditions, the pattern of mortality in the CoCT continues to reflect a quadruple burden of disease, with HIV/AIDS, other communicable diseases, injuries and NCDs all accounting for a significant proportion of deaths. Further declines in child mortality will require interventions targeted at LRTI and perinatal causes of death. Declining mortality from HIV/AIDS, TB and homicide has highlighted the emerging burden of NCDs in adults. In particular, IHD, stroke, diabetes mellitus and cancers of the lung and breast require attention, and mortality rates from breast, cervix, prostate and colon cancer have increased.

\section{Study limitations}

This analysis is limited by incompleteness of death reporting to the LMSS, which was low during the years in which mortality peaked in the CoCT (Appendix 2). This has necessitated comparing mortality rates 




Fig. 5. Changes in firearm and non-firearm homicide mortality for males in high-burden subdistricts of the CoCT between 2001 - 2004 and 2010 - 2013. (CoCT = City of Cape Town.)

before the peak with rates after the peak, complicating the interpretation of any changes. Changes in coding, from manual coding using a shortlist of 120 causes to automated ICD-10 coding, have complicated the interpretation of changes in single causes which are subject to misclassification because of poor certification practices, particularly for cardiovascular diseases and diabetes mellitus. In addition, no attempt was made to adjust for underreporting of HIV due to misclassification to immediate causes.

\section{Conclusions}

Trends in mortality in the past decade indicate some welcome gains in health and equity, particularly among U5 children. Although they show the need for multisectoral interventions to focus on LRTI in children and HIV/AIDS and TB, homicide and injuries and the emerging epidemic of NCDs in adults, the mortality trends also highlight that the greatest reductions have occurred among the poorest communities, despite increasing HIV prevalence and a relatively stable TB reported incidence. This serves as an encouraging finding to policy makers to counter increasing empirical evidence of the 'trickle-down' pattern of health systems strengthening, where improvements often affect better-off groups before they affect poorer groups. ${ }^{[27]}$ Injury mortality rates are still very high compared with global averages, and a recent increase in homicides in the CoCT from 2012 needs urgent attention and investigation. ${ }^{[28]}$ HIV/AIDS and TB mortality rates remain high despite the declining trend, and the large number of people requiring chronic medication for the rest of their lives continues to grow. The NCD epidemic will add to the need for chronic care. Ongoing monitoring of mortality rates by cause at subdistrict level is essential to ensure that favourable trends persist and that inequities are further reduced. Unfortunately, owing to changes in the regulations pertaining to the Births and Deaths Registration Act ${ }^{[29]}$ promulgated in 2014, access to death certificates has been denied to the City Health directorate by the Department of Home Affairs since February 2014, ${ }^{[30]}$ effectively shutting down the LMSS. In view of the wealth of data provided by the LMSS to inform planning, implementation and evaluation of targeted interventions at health subdistrict level, the resumption of this mortality surveillance should receive urgent high-level attention.

Acknowledgements. Co-operation from City Health, the offices of the Department of Home Affairs and the Forensic Pathology Services in the Western Cape is acknowledged. The authors thank Profs Lorna Martin and Johan Dempers, Mrs Vonita Thompson and Mr Michael Vismer for providing access to forensic pathology data, Mrs Kulsum Cornelius and data capturers from City Health and the Western Cape Provincial Department of Health for capturing the data, and Marcel Berteler of Health Information, CoCT, for developing and maintaining the webbased data capture system.

Author contributions. PG, RM and DB were responsible for the design and implementation of the study; TN, JE and JD were responsible for data capture and cleaning and contributed to the analysis; IN was responsible for data management and analysis; NN contributed to the analysis of child mortality; VA provided input on City Health interventions that impacted on mortality trends; PG and DB were responsible for drafting the manuscript; and all authors contributed to reviewing and finalising the manuscript.

Funding. Funding from the South African Medical Research Council and the Western Cape Provincial Department of Health is acknowledged.

Conflicts of interest. None. 
1. Document No. A/69/970. Report of the open working group of the General Assembly on Sustainable Development Goals. In: 68th Session of the United Nations General Assembly New York 12 Aug

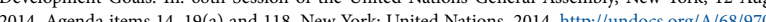
2014. Agen 16 items $14,19(a)$ a (acessed 16 rebria 2016$)$

alth inequalities and the health of the poor: What do we know? What can we do? Bull World Health Organ 2000;78(1):3-18. https://doi.org/10.1590/\$0042-96862000000100002

3. Bradshaw D, Groenewald P, Laubscher R, et al. Initial burden of disease estimates for South Africa, 2000. S Afr Med J 2003;93(9):682-688

4. Bradshaw D, Groenewald P, Bourne D, et al. Making cause of death statistics useful for public health at local level in the City of Cape Town. Bull World Health Organ 2006;84(3):211-217. https://doi. org/10.1590/S0042-96862006000300016

5. South Africa. Inquest Act No. 58 of 1959

6. Groenewald P, Bradshaw D, Daniels J, et al. Local-level mortality surveillance in resource-limited settings: A case study of Cape Town highlights disparities in health. Bull World Health Organ 2010;88(6):444-451. https://doi.org/10.2471/BLT.09.069435

7. Groenewald P, Msemburi W, Morden E, et al. Western Cape Mortality Profile 2011. Cape Town: South African Medical Research Council, 2014. http//www mrc ac za/bod/WC2011Report pdf (accessed 15 February 2016)

8. Naledi T, Househam K, Groenewald P, Bradshaw D, Myers JE. Improving data to reduce the burden of 8. Naledi T, Househam K, Groenewald P, Bradshaw D, Myers JE. Improving
disease - lessons from the Western Cape. S Afr Med J 2009:99(9):641-642.

9. Johansson L, Pavillon G, Pelikan L, Weber S. IRIS Automated Coding System for Causes of Death. User's Reference Manual (IRIS version V4.1.3). Cologne: IRIS Institute, DIMDI, 2012.

User's Reference Manual (IRIS version V4.1.3). Cologne: IRIS Institute, DIMDI, 2012.
. World Health Organization. International Statistical Classification of Diseases and Related Health 0. World Health Organization. International Statistical
Problems. 10th revision, vol. 2. Geneva: WHO, 1993.

Problems. 10th revision, vol. 2. Geneva: WHO, 1993 .
1. Groenewald P, Bradshaw B, Neethling I, et al. Linking mortuary data improves vital statistics data on causes of death in children under five years in the Western Cape Province of South Africa. Trop Med Int Health 2016;21(1):114-121. https://doi.org/10.1111/tmi.1262

12. Statistics South Africa. Mortality and Causes of Death in South Africa, 2010: Findings from Death Notification. Statistical release P0309.3. Pretoria: SSA, 2013.

13. Pillay-Van Wyk V, Laubscher R, Msemburi W, et al. Second South African National Burden of Disease Study: Data Cleaning, Validation and SA NBD List (Technical Report). Cape Town: Burden of Disease Research Unit, South African Medical Research Council, 2014. http://www mrc ac za/bod/ SANBDReport.pdf (accessed 6 November 2017)

14. Liu L, Johnson HL, Cousens S, et al., for the Child Health Epidemiology Reference Group of WHO and UNICEF. Global, regional, and national causes of child mortality: An updated systematic analysis for 2010 with time trends since 2000. Lancet 2012;379(9832):2151-2161. https://doi.org/10.1016/S01402010 with time trends since 2000. Lancet 2012;379(9832):2151-2161. https://doi.org/10.1016/50140-
6736(12)60560-1 6736(12)60560-1

15. Dorrington RE. Alternative South African mid-year estimates, 2013. Centre for Actuarial Research Monograph 13, University of Cape Town

16. Ahmad OB, Boschi-Pinto C, Lopez AD, Murray CJL, Lozano R, Inoue M. Age Standardization of Rates: A New WHO Standard. GPE Discussion Paper Series, No. 31. EIP/GPE/EBD. Geneva: World Health Organization, 200

17. Boyle P, Parkin DM. Statistical methods for registries. In: Jensen OM, Parkin DM, MacLennana R, Muir CS, Skeet RG, eds. Cancer Registration: Principles and Methods. IARC Scientific Publication No. 95. Lyon: International Agency for Research on Cancer, 1991:126-158.

18. National Department of Health, South Africa. The National Antenatal Sentinel HIV and Syphilis Prevalence Survey, South Africa, 2011. Pretoria: $\mathrm{NDoH}, 2012$.

19. Department of Health, Western Cape. National Antenatal Sentinel HIV Prevalence Survey, South Africa: Abbreviated Western Cape Results. Cape Town: DoH Western Cape, 2014.

20. Department of Health, Western Cape. The 2005 HIV Antenatal Provincial and Area Surveys, Western Cape. Cape Town: DoH Western Cape, 2006.

1. Petros M. Foreword from the Provincial Commissioner. MADAM Newsletter 2005;July/August, p. 2. 22. South Africa. Firearms Control Act No. 60 of 2000

22. South Africa. Firearms Control Act No. 60 of 2000.
23. Ellis E. Licence applicants stick to their guns. The Star 2003;1 September, p. 13 .

24. Matzopoulos R, Groenewald P, Abrahams N, Bradshaw D. Where have all the gun deaths gone? S Afr Med J 2016;106(6):589-591. https://doi.org/10.7196/SAMJ.2016.v106i6.10379
25. Matzopoulos RG, Thompson M Lou, Myers JE. Firearm and nonfirearm homicide in 5 South African cities: A retrospective population-based study. Am J Public Health 2014;104(3):455-460. https://doi. org/10.2105/APPH.2013.310650

26. Abrahams N, Mathews S, Martin LJ, Lombard C, Jewkes R. Intimate partner femicide in South Africa in 1999 and 2009. PLoS Med 2013;10:e1001412. https://doi.org/10.1371/journal.pmed.1001412

27. Gwatkin DR, Ergo A. Universal health coverage: Friend or foe of health equity? Lancet 2011;377(9784):2160-2161. https://doi.org/10.1016/S0140-6736(10)62058-2

28. Morden E, Groenewald P, Zinyakatira N, et al. Western Cape Mortality Profile 2013. Cape Town: South African Medical Research Council, 2016

29. South Africa. Births and Deaths Registration Act No. 51 of 1992. Regulations on the Registration of Births and Deaths, 2014. Government Gazette 26 February 2014;584(37373):5-74. http://www.gov.za/ sites/www.gov.za/files/a51_1992.pdf (accessed 22 May 2015).

30. Bateman C. Another law change prevents proper healthcare delivery. S Afr Med J 2015;105(4):244-245. https://doi.org/10.7196/SAMJ.9553

Accepted 11 August 2017.

Supplementary information: http://www.mrc.ac.za/bod/coct.htm

Appendix 1. Percentage of households with an income of less than ZAR3 200 per month by health subdistrict, City of Cape Town (source: Census 2011).

Appendix 2. Completeness of City of Cape Town local mortality surveillance data.

Appendix 3. Mapping of the National Burden of Disease list to ICD-10 codes.

Appendix 4. Changes in age-specific death rates for tuberculosis and HIV in three high-burden subdistricts of the City of Cape Town between 2001 - 2004 and 2010 - 2013.

Appendix 5. Age-standardised mortality rates by single cause for the City of Cape Town and subdistricts, 2001 - 2004 and 2010 - 2013.

Appendix 6. Leading causes of death by gender, City of Cape Town, $2001-2004$ and $2010-2013$. 